\title{
Lumbar epidural hematoma following lumbar puncture: the role of high dose LMWH and late surgery. A case report
}

\author{
D. Gurkanlar; C. Acikbas; G.K. Cengiz and R. Tuncer
}

Department of Neurosurgery. Akdeniz University. School of Medicine. Antalya. Türkiye.

\section{Summary}

Spinal epidural hematoma (SEH) is a known complication of spinal surgery, but the incidence of post-surgical SEHs that result in neurologic deficits is extremely rare $(0.1 \%)$. Patients that require multilevel lumbar procedures and/or have a preoperative coagulopathy are at a significantly higher risk of developing an epidural hematoma. The introduction of higher dose of low molecular weight heparin (LMWH) twice daily 30 mg regimen) increased the reported incidence of neuroaxial hematomas. Surgery performed within 8 hours makes good or partial recovery of neurologic function.

Our patient was also started on higher dose of LMWH and developed neurological deficits due to a SEH following lumbar puncture. She underwent operation after six days and she had a mild recovery following the operation.

Current administration of high doses of LMWH can cause SEH even after a lumbar puncture, which was performed without multiple attempts.

Although surgery performed within 8 hours makes good or partial recovery of neurologic function, laminectomy and epidural hematoma evacuation performed after three days can also have successful results.

KEY WORDS: Lumbar. Epidural hematoma. Surgery. LMWH. Myelography.

Hematoma lumbar epidural postpunción lumbar; influencia de dosis altas de LMWH y cirugía diferida

\section{Resumen}

El hematoma espinal epidural (HEE) es una complicación conocida en la cirugía espinal, pero la incidencia del HEE que da lugar a déficit neurológico es muy rara $(0,1 \%)$. Los pacientes que necesitan intervenciones en

Recibido: 26-06-05. Aceptado26-04-06 varios niveles lumbares y/o que tienen una coagulopatía preoperatoria tienen un riesgo significativamente mayor de desarrollar un hematoma epidural. La introducción de dosis altas de heparina de bajo peso molecular (HBPM), (30 mgrs. dos veces al día) aumentan la incidencia de hematomas neuroaxiales. La cirugía llevada a cabo dentro de las 8 horas da lugar a un recuperación buena o parcial de la función neurológica.

Nuestro paciente fue tratada con dosis altas de HBPM y desarrolló un déficit neurológico debido a un HEE, después de una punción lumbar. Fue operada al cabo de seis días y se recuperó parcialmente de su déficit después de la intervención.

La administración actual de dosis altas de HBPM puede dar lugar a HEE, incluso después de una punción lumbar, que se hizo en pocos intentos.

Aunque la cirugía realizada en las primeras 8 horas produce una recuperación buena o parcial, la laminectomía y evacuación del hematoma llevada a cabo después de tres días también puede dar lugar a buenos resultados.

PALABRAS CLAVE: Lumbar. Hematoma epidural. Cirugía. HBPS. Mielografía.

Introduction

Multilevel lumbar procedures, anatomic abnormalities, traumatic puncture with multiple attempts, and coagulation disorders or anticoagulation therapy are significant risk factors for spinal epidural hematoma development ${ }^{11,5}$. As well as most of them are clinically insignificant, but may cause severe and rapid neurological deterioration.

We report a case of a woman developing epidural hematoma with neurological deterioration three days after

Abbreviations. CMT: computerized myelo-tomography. CT: computerized tomography. HBPM: heparina de bajo peso molecular. HEE: hematoma epidural espinal. LMWH: low molecular weight heparin. MRI: resonancia magnética. SEH: spinal epidural hematoma. 


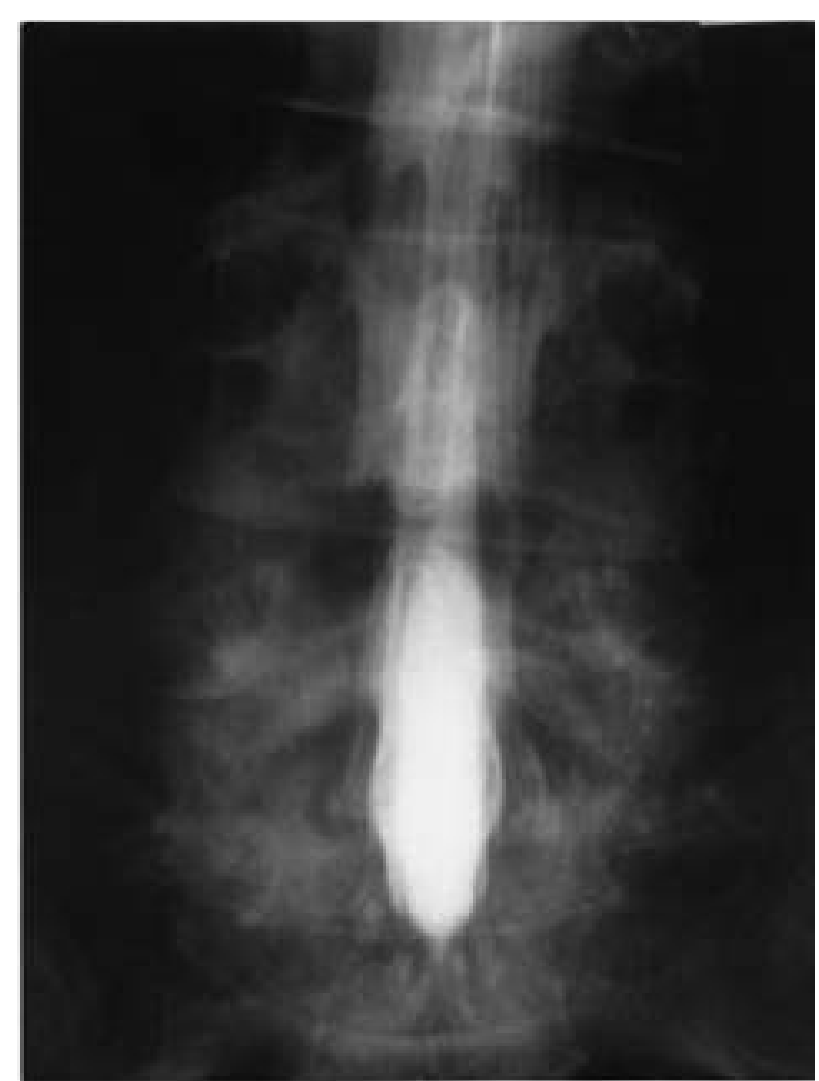

Figure 1. Lumbar myelogram demonstrating abrupt termination of the right L5 root.

a lumbar puncture, whose hematoma was removed by laminectomy.

\section{Case}

A 51-year-old woman suffering from right leg pain was admitted to our hospital. Her neurologic examination revealed only the right positive straight leg raising test, at $45^{\circ}$. The patient had had atrial and mitral valve replacement operations in 1988 and 1998. Therefore we could not perform magnetic resonance imaging (MRI). We could only performed lumbar myelography and computerized myelography (CTM) three weeks after stopping her coumadine treatment. The patient received low molecular weight heparin $(\mathrm{LMWH})(60 /$ day) during this period and her coagulation variables were in normal limits. Lumbar myelogram which was performed at L3-4 level, demonstrated abrupt termination of the right L5 root (Figure 1) and CTM showed the posterolateral disc herniation which prevented filling of the nerve root (Figure 2). After this examination, conservative therapy was started due to the absence of significant neurologic deficit and the patient was discharged. After the lumbar puncture, the patient began to suffer from persistent low back pain, progressive right leg weakness

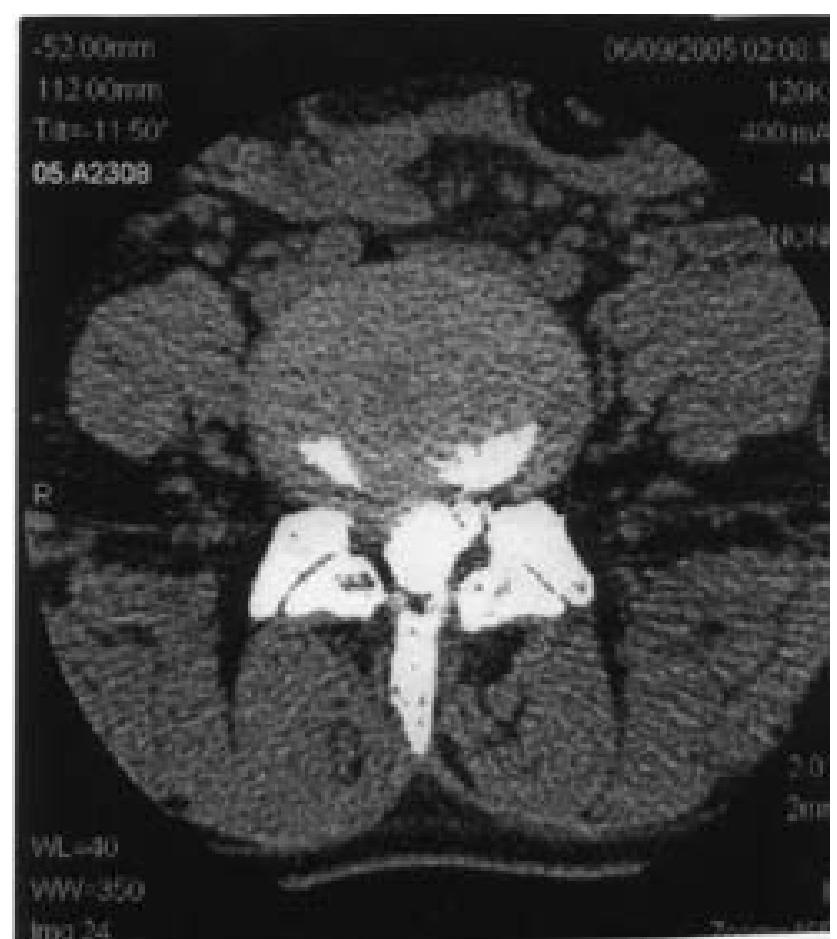

Figure 2. CTM showing the posterolateral disc herniation which prevented filling of the nerve root.

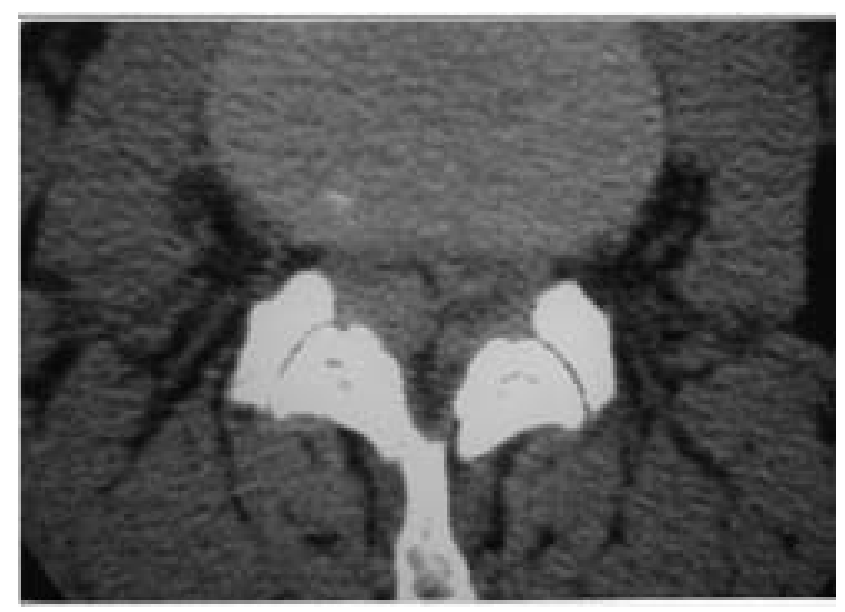

Figure 3. CT of the lumbar region revealed a right dorsolateral isodense mass causing compression of the techal sac at L2-3 level.

and numbness. Although her motor weakness began immediately after the lumbar puncture, it was apparent on the third day of the course. She was admitted to our outpatient clinic again on the sixth day of lumbar puncture and her neurological examination revealed 2/5 motor strength of right lower extremity, hypoesthesia below L1 level and loss of Achilles and patellar reflexes. The CT study of the lumbar region revealed a right dorsolateral isodense mass 
causing compression of the techal sac at L2-3 level (Figure 3 ) and a right sided L 2 hemiparcial laminectomy performed immediately. A soft red-bluish mass, without fluid parts, measuring nearly $4 \mathrm{~cm}$, extending from right dorsolateral to the left dorsolateral side of the tecal sac, with a capsule was reached following flavectomy and decompression, by evacuation of the hematoma, was performed. After the hematoma removal we recognized that the lumbar puncture had been performed at the L2-3 space. The final pathological diagnosis of the operation material was organized hematoma. Postoperative CT revealed no hematoma at operation site. Immediately after the operation the back pain resolved. The strength of the right lower extremity was $3 / 5$ proximally and $2 / 5$ distally, at discharge.

\section{Discussion}

Spinal epidural hematoma (SEH) is a known complication of spinal surgery $1^{1,9,16,18}$, but the incidence of postoperative SEHs that result in neurologic deficits is extremely rare. Lawton et $\mathrm{a}^{14}$ reported the incidence rate to be $0.1 \%$. Postoperative epidural hematoma should be suspected in the patient who either demonstrates a new postoperative neurologic deficit or develops deficits in the immediate postoperative period that are consistent with cauda equina syndrome $^{11}$. SEH will cause spinal pain and root pain, followed by a progressive neurologic deterioration, whose features will be dependent on the level of compression? $\mathrm{SEH}$ is a significant cause of morbidity and needs to be diagnosed as early as possible because the timing of decompression and evacuation of the hematoma is critical $^{11}$.

Patients that require multilevel lumbar procedures and/or have a preoperative coagulopathy are at a significantly higher risk of developing an epidural hematoma ${ }^{11}$. Anatomic abnormalities, traumatic puncture with multiple attempts, and coagulation disorders or anticoagulation therapy are also risk factors for spinal epidural hematoma development ${ }^{5}$. Spontaneous epidural hematomas have been reported in those with liver and autoimmune disease ${ }^{13,17}$. They have also been associated with thrombolytic therapy and anticoagulants ${ }^{1,9,12}$.

Anticoagulation therapy especially with LMWH and coagulation disorders are the main risk factors in the formation of spinal epidural hematoma following lumbar puncture $^{19}$. The introduction of higher dose of LMWH (twice daily $30 \mathrm{mg}$ regimen) in the United States increased the reported incidence of neuroaxial hematomas compared with what was reported in Europe $(30 \mathrm{mg} / \mathrm{day})^{6}$.

Although the lumbar puncture was performed in one attempt and the coagulation variables were in normal ranges, an epidural hematoma and related symptoms occurred in our patient probably due to a coagulopathy.
Vandermeulen et $\mathrm{al}^{23}$ found that most patients with an SEH that were decompressed surgically within 8 hours made good or partial recovery of neurologic function. We operated our patients on the sixth day of complaints however it is too late for surgery according to Vandermeulen and Delamarten ${ }^{3,23}$. After the surgery the patient was free of pain and her neurologic examination revealed marked improvement of the neurologic deficits.

The insertion site (thoracic vs. lumbar) and the midline or paramedian approach of the epidural space are sometimes believed to increase the risk of epidural bleeding. There is no evidence that the risk for hematoma formation is lower with a midline compared with paramedian appro$\mathrm{ach}^{22,7}$. However, the paramedian technique may need more attempts and have o lower success rate compared with the midline technique ${ }^{10}$.

Bleeding from smaller vessels of the ligamentum flavum $^{15,21}$ and arterial bleeding can also cause spinal epidural hematomas ${ }^{8}$. Some authors also believe that lumbar epidural bleeding could result from rupture of an epidural vein either by a sudden increase in the intraabdominal pressure impacting on a previously damaged or weakened vein, or by mild trauma ${ }^{2,4,20}$.

In our case the lumbar puncture was performed at L2-3 space instead of L4-5 in one attempt. However, we could not have found any exact data about lumbar puncture which if it is performed at higher lumbar levels increases epidural hematoma occurrence.

\section{Conclusion}

Current administration of high doses of LMWH can cause SEH even after a lumbar puncture, which was performed without multiple attempts.

Although surgery performed within 8 hours made good or partial recovery of neurologic function, laminectomy and epidural hematoma evacuation performed after three days can also have successful results.

\section{References}

1. Cohen, J.E., Ginsberg, H.J., Emery, D., et al.: Fatal spontaneous spinal epidural hematoma following thrombolysis for myocardial infarction. Surg Neurol 1998; 49: 520-522.

2. Coope,r D.W.: Spontaneous spinal epidural hematoma. J Neurosurg 1967; 26: 343-345.

3. Delamarter, R.B., Sherman, J., Carr, J.B.: Pathophysiology of spinal cord injury: recovery after immediate and delayed decompression. J Bone Joint Surg Am 1995; 77 : 1042- 1049.

4. Groen, R.J.M., Ponssen, H.: The spontaneous spinal epidural hematoma. A study of aetiology. J Neurol Sci 1990; 98: 121-138. 
5. Horlocker, T.T.: Low molecular weight heparin and neuroaxial anesthesia. Thrombosis Res 2001; 101: 141-154.

6. Horlocker, T.T., Wedel, D.J.: Neuroaxial blockade and low molecular weight heparin. Balancing preoperative analgesia and thromboprophylaxis. Reg Anesth 1998; 23: 164-177.

7. Horlocker, T.T., Wedel, D.J., Schroeder, D.R., Rose, S.H., Elliot, B.A., McGregor, D.G., et al.: Preoperative antiplatelet therapy does not increase the risk of spinal hematoma associated with regional anesthesia. Anesth Analg 1995; 80: 303-309.

8. Houten, K.J., Ericco, T.J.: Paraplegia after lumbosacral nerve root block: report of three cases. The Spine Journal 2002; 2 : 70-75.

9. Johnston, R.A.: The management of acute spinal cord compression. J Neurol Neurosurg Psychiatry 1993; 56: 10461054.

10. Kopacz, D.J., Neal, J.M., Pollock, J.E.: The regional anesthesia 'learning curve': what is the minimum number of epidural and spinal blocks to reach consistency? Reg Anesth 1996; 21: 182-190.

11. Kou, J., Fischgrund, J., Biddinger, A., Herkowitz, H.: Risk factors for spinal epidural hematoma after spinal surgery. Spine 2002; 27: 1670-1673.

12. Krolick, M.A., Cintron, G.B.: Spinal epidural hematoma causing cord compression after tissue plasminogen activator and heparin therapy. South Med J 1991; 84: 670-671.

13. Laglia, A.G., Eisenberg, R.L., Weinstein, P.R., et al.: Spinal epidural hematoma after lumbar puncture in liver disease. Ann Intern Med 1978; 88: 515-516.

14. Lawton, M.T., Porter, R.W., Heiserman, J.E., et al.: Surgical management of spinal epidural hematoma: relationship between surgical timing and neurological outcome. J Neurosurg 1995; 83: 1-7.

15. Lunardi, P., Mastronardi, L., Lo Bianco, F., Schettini,
G., Puzzilli, F.: Chronic spontaneous spinal epidural haematoma simulating a lumbar stenosis. Eur Spine J 1995; 4: 6466.

16. Mayfield, F.H.: Complications of laminectomy. Clin Neurosurg 1976; 23: 435-439.

17.Mohazab, H.R., Langer, B., Spigos, D.: Spinal epidural hematoma in a patient with lupus coagulopathy: MR findings. AJR 1993; 160: 853-854.

18. Pear, B.L.: Spinal epidural hematoma. AJR 1972; 115: 155-164.

19. Persson, J., Flisberg, P., Lundberg, J.: Thoracic epidural anesthesia and epidural hematoma. Acta Anesthesiol Scand 2002; 46: 1171-1174.

20. Schwartz, F.T., Sartavi, M.A., Fox, J.L.: Unusual hematomas outside the spinal cord. J Neurosurg 1973; 39: 249-251.

21. Sweasey, T.A., Coester, H.C., Rawal, H., Blaivas, M., Mcgillicuddy, J.E.: Ligamentum flavum hematoma. Report of two cases. J Neurosurg 1992; 76: 534-537.

22. Tanaka, K., Watanabe, R., Harada, T., Dan, K.: Extensive application of epidural anesthesia and analgesia in a University hospital: Incidence of complications related to technique. Reg Anesth 1993; 18: 34-38.

23. Vandermeulen, E.P., Aken, H.V., Vermylen, J.: Anticoagulants and spinal-epidural anesthesia. Anesth Analg 1994; 79: 1165-1177.

Gurkanlar, D.; Acikbas, C.; Cengiz, G.K.; Tuncer, R.: Lumbar epidural hematoma following lumbar puncture: the role of HIGH dose lmwh and late surgery. A case report. Neurocirugía 2007; 18: 52-55.

Corresponding author: Dr. Doga Gurkanlar M.D. Yeşilbahçe Mahallesi. Portakal Çiçeği Antalya. Türkiye. 